\title{
Use of Spreadsheets to Teach Mathematical Applications in Economics
}

\author{
Muhammad Ahsanuddin ${ }^{1}$, Mushtaq Ahmed ${ }^{2}$, Saba Naz ${ }^{2}$
}

\author{
${ }^{1}$ Department of Economics, University of Karachi, Pakistan \\ ${ }^{2}$ Department of Mathematics, University of Karachi, Pakistan
}

\begin{abstract}
The use of spreadsheets is increasing with the passage of time. Concepts are made clear and problems are made easier to understand by teaching economics using spreadsheets. In the contemporary world new concepts are evolving fast where mathematical formulations and graphical analysis are a requirement. In this regard the use of spreadsheets saves time for tedious computations as well as makes available new styles and techniques. The use of computers in economic analysis is increasing and there is a growing computational environment and extensive use of functions with content-specific templates employed in teaching methods. In modern times students of economics and people from different professions carry out routine work with the help of MS office and Excel spreadsheets. These can be used for simulating the impact of movements in conic sections by economists and mathematicians studying a plethora of phenomena. Students of economics, physics and mathematics must learn how to exploit spreadsheets for data analysis and programing purposes which is a need of time. In this manuscript we have shown two examples of mathematical applications to economics. In one of the examples we showed determination of equilibrium point graphically. The second example is unique in a sense that it covers optimization with some constraints in nonlinear programming. The optimal point is found through simulation.
\end{abstract}

\section{INTRODUCTION}

Microsoft's widespread Office software package includes Excel which is popularly utilized for the managing, investigating and employing economic data. The user-friendly features include chart wizard as well data examining capabilities. Excel is extensively employed in various economic courses for data analysis as many data sets are available in Excel-ready formats for pupils to get hands-on practice using economic theories and concepts.

The use of Spreadsheet software has increased manifold over the passage of time. Spreadsheets are commonly utilized for data compilation and computation. Other than arithmetic, spreadsheets can be formatted to make reports that can be organized and restructured effortlessly. The widely use applications of spreadsheet software include creating budgets, producing graphs and charts and for sorting and storing data. In economics spreadsheet software is employed to predict future trends, tax calculation, compilation of payrolls as well estimating revenues. Cahill and Kosicki (2001) demonstrate a framework for thinking about the various forms of spreadsheet modeling usages available for teaching economics. They formulate various applications of spreadsheets and are of the opinion that the teacher can modify applications as per his or her teaching requirements. In another paper Cahill and Kosicki (2000) make use of Excel in IS-LM model to make understand the ideas of money neutrality, the permanent income hypothesis and rational expectations. Similarly, Craft (2003) argues that to elucidate Monte Carlo simulations spreadsheets can be used to save invaluable time and costs. Correspondingly, various studies show the applications for spreadsheet software in teaching students of various subjects (Abramovich et al., 2010; Baker \& Sugden, 2004; Uddin et al., 2017). In mathematics education the aspects of spreadsheets are to enable students to formulate links between diverse content areas that might else be developed separately (Beare, 1993). Neuwirth \& Arganbright (2004) show numerous tutorials and applications to solve problems in Excel applicable in mathematical modeling.

The objective of this study is to let instructors to tailor spreadsheet applications to serve many diversified instructional goals in sundry instructional settings.

\section{METHODOLGY}

Two examples are being presented in this study, one of them deals with the identification of equilibrium points when two demands curves are given, and the second example deals with linear programming and optimization problem.

This article is published under the terms of the Creative Commons Attribution License 4.0 Author(s) retain the copyright of this article. Publication rights with Alkhaer Publications. Published at: http://www.ijsciences.com/pub/issue/2019-04/

DOI: 10.18483/ijSci.2018; Online ISSN: 2305-3925; Print ISSN: 2410-4477 


\section{Determination of equilibrium point:}

When supply and demand curves are given, the equilibrium price and demand values can be found by plotting both the curves on price demand graph (Mabbett, 1986). The two curves intersect at a point, the values of price and demand corresponding to that point are equilibrium price and demand, respectively. In an Excel sheet, demand and supply curves are plotted by inserting information of slope and intercept of demand equation in cells $\mathrm{C} 3$ and $\mathrm{C} 4$, respectively, whereas the information of slope and intercept of supply equation are inserted in cells C7 and $\mathrm{C} 8$, respectively. Once the information is updated the spreadsheet draws both the straight lines and the point of intersection is found and equilibrium price and demand are displayed in cells M3 and M4, respectively (see fig. 1). When information of slopes and demands are updated, new lines are drawn, and new equilibrium point is displayed. The equations of the straight lines are also displayed on the graph.

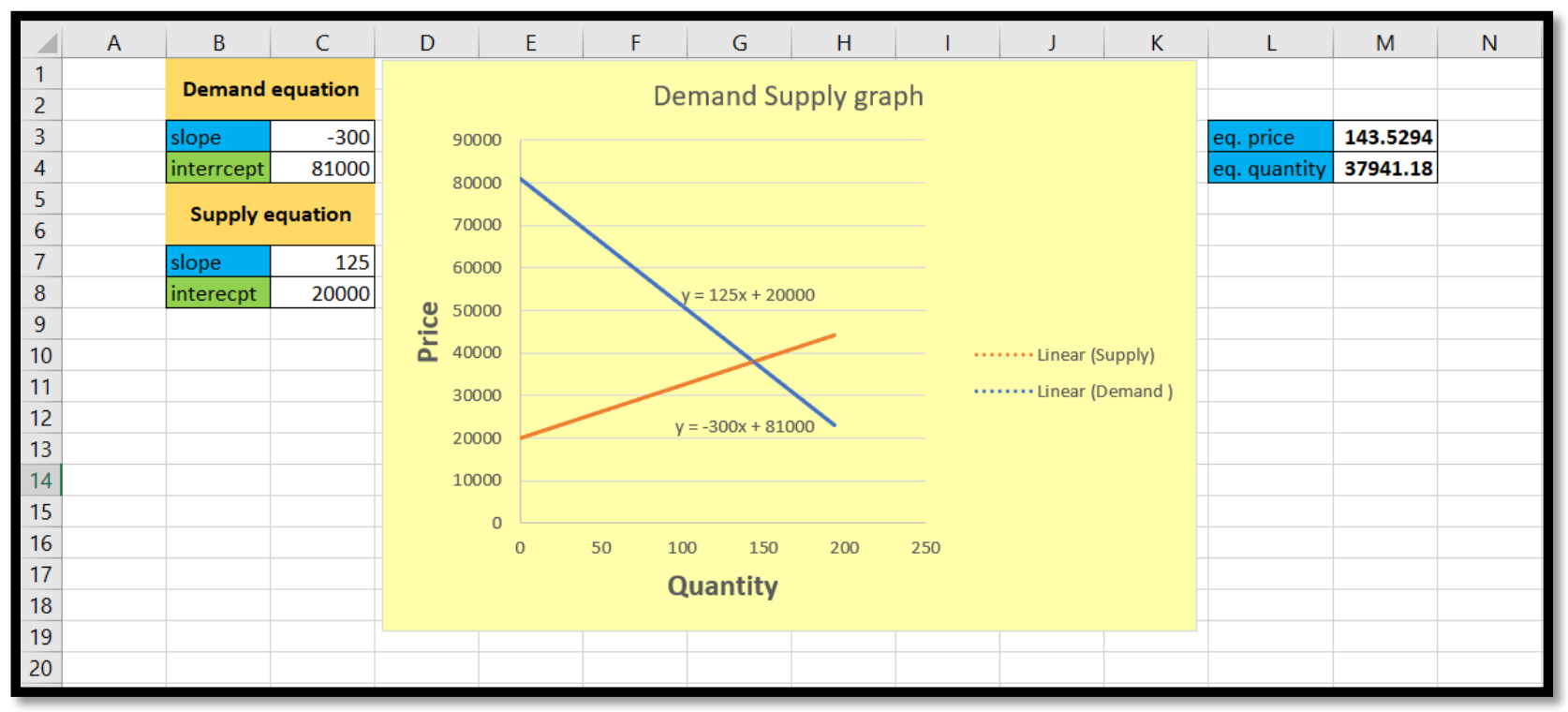

Fig. 1. Determination of equilibrium point graphically.

The second example is from optimization problem in nonlinear programming. It is a solved example (Chiang, 1987). In this problem we use the equation of a circle to find value of $\mathrm{c}$ that minimizes the given function on constraints which are linear inequalities. The problem is to minimize

subject to the constraints

$$
C=\left(x_{1}-4\right)^{2}+\left(x_{2}-4\right)^{2}
$$

$$
\begin{gathered}
2 x_{1}+3 x_{2} \geq 6 \\
-3 x_{1}-2 x_{2} \geq-12 \\
x_{1}, x_{2} \geq 0
\end{gathered}
$$

In spreadsheet this problem is simulated.
The center of the circle is $(4,4)$ and are shown in cells (B2, B3), the constraints equations are written in cells A5:G5, A6:G6, A7:C7 and A8:C8. The spin-button controls the value of the radius of the circle drawn on graph, the value is mentioned in cell $\mathrm{K} 1$. The value of cell $\mathrm{K} 1$ can be continuously changed using spinbutton. When radius in cell $\mathrm{K} 1$ equals the distance between center of the circle and one of the constraint lines, the optimal point is obtained (see fig. 2), the optimal point is displayed in cells (J10, K10). The sheet can be used for different radii and constraint equations. The values will be changed in cells having blue color. 


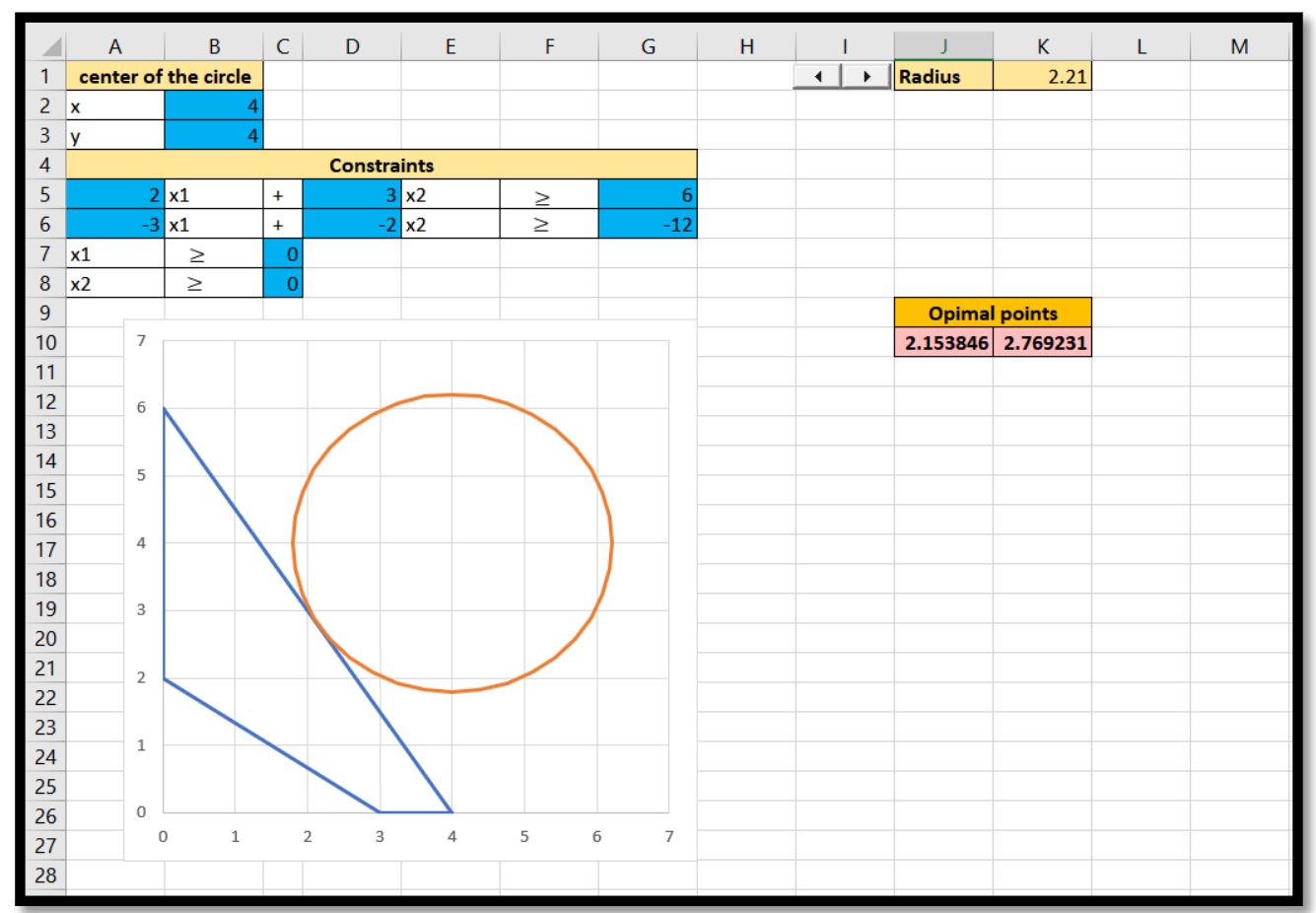

Fig. 2. Simulation of optimization process in nonlinear programming.

\section{CONCLUSION}

This study demonstrates that the application of spreadsheets can help in capturing movements in straight lines and circles having different impacts on countless demand and supply situations. Graphical representation of calculation results in dimensions higher than three can be visualized and easily understood. This can benefit researchers and students alike studying the interplay of market forces in different situations. Of course, different situations are instrumental in varied economic outcomes in a society. As has been shown, spreadsheets because of their mathematical and graphical capabilities can provide an exceptionally good environment for a variety of instructional usages in economics.

Spreadsheets enable users to extensively employ data, mathematical designs and graphs, and undertake arguments built on quantitative evidence which offer an opportunity for pupils to learn and enhance fluency in numerical methods.

We presented two examples from economics in which application of mathematics is portrayed. One of the examples is related to determination of equilibrium point when two linear functions of supply and demand are given. The spreadsheet can be used for similar situations if values of slopes and intercepts are changed in corresponding cells. In second example optimization problem is simulated. In this example the optimal point is obtained by varying radius to an optimal point where one of the constraint lines becomes tangent to the circle. We conclude that spreadsheets are one of the means of transferring knowledge visually.

\section{REFERENCES}

1. Abramovich, S., Nikitina, G. V., \& Romanenko, V. N. (2010). Spreadsheets and the development of skills in the STEM disciplines. Spreadsheets in Education, 3(3), 4565.

2. Baker, J., \& Sugden, S. J. (2004). Spreadsheets in educationThe first 25 years. Spreadsheets in Education, 1(1), 4511.

3. Beare, R. (1993). How spreadsheets can aid a variety of mathematical learning activities from primary to tertiary level. Technology in mathematics teaching: A bridge between teaching and learning, 117-124.

4. Cahill, M. B., \& Kosicki, G. (2000). Incorporating neoclassical assumptions into IS-LM, Computers in Higher Education Economics Review (CHEER), 14: 2.

5. Cahill, M. B., \& Kosicki, G. (2001). A framework for developing spreadsheet applications in economics. Social Science Computer Review, 19(2), 186-200.

6. Chiang, A. C. (1987). Fundamental methods of mathematical economics. $3^{\text {rd }}$ Ed. NY: McGraw-Hill/Irwin, 701p..

7. Craft, R. K. (2003). Using spreadsheets to conduct Monte Carlo experiments for teaching introductory econometrics. Southern Economic Journal, 726-735.

8. Mabbett, A. J. (1986). Work out mathematics for economists. Macmillan Education Ltd Houndmills, Basingstoke, Hampshire RG21 2XS and London.

9. Needham, T. C. (2018). Excel 2016: A Comprehensive Beginner's Guide to Microsoft Excel 2016. WhiteFlowerPublsihing.

10. Neuwirth, E., \& Arganbright, D. (2004). The active modeler: Mathematical modeling with Microsoft Excel. Thomson/Brooks/Cole.

11. Uddin, Z., Ahsanuddin, M., \& Khan, D. A. (2017). Teaching physics using Microsoft Excel. Physics Education, 52(5), 053001 . 